\title{
MiR-21-5p inhibition attenuates Warburg effect and stemness maintenance in osteosarcoma cells via inactivation of $\mathrm{Wnt} / \boldsymbol{\beta}$ - catenin signaling
}

\author{
Ziyan Wü, Zhong Zhou\#, Weiguo Zhang and Yi Yu凶 \\ Department of Orthopedics, The Central Hospital of Wuhan, Tongji Medical College, Huazhong University of Science and Technology, Wuhan \\ 430016, China
}

\begin{abstract}
MicroRNA (miR)-21 has been found to be overexpressed in osteosarcoma (OS). The aim of the present study was to investigate the effect of miR-21-5p on the Warburg effect and stemness maintenance in OS cells and its potential molecular mechanism. Herein, miR-21-5p was overexpressed or inhibited in MG-63 cells via transfection with mimics or inhibitors. The effect of miR-21-5p on cell viability, apoptosis, Warburg effect and stemness maintenance were explored in OS cells. The results demonstrated that miR-21-5p inhibition suppressed MG-63 cell viability and enhanced their apoptosis. Additionally, miR-21-5p inhibition attenuated the stemness maintenance of MG-63 cells, as demonstrated by the reduced proportion of CD133-positive MG-63 cells, the decrease in tumorsphere formation capacity, and the downregulation of Sox2, Oct4, and Nanog proteins. Moreover, miR-21-5p inhibition suppressed the Warburg effect in MG-63 cells, as indicated by the decrease in glucose uptake, lactic acid production, and ATP level and the downregulation of proteins involved in the Warburg effect (GLUT1, LDHA, HK2, and PKM2). Furthermore, the results suggested that the effect of miR-21-5p suppression on stemness and the Warburg effect may be associated with the decreased activity of the $\mathrm{Wnt} / \beta$-catenin pathway in OS cells. Our findings suggest a novel potential biomarker for OS therapy.
\end{abstract}

Keywords: osteosarcoma; MiR-21-5p; Warburg effect; stemness; Wnt/ $\beta$-catenin pathway

Received: 15 March, 2021; revised: 15 April, 2021; accepted: 11 May, 2021; available on-line: 25 October, 2021

๑e-mail: 117228559@qq.com

\#The authors contributed equally

Acknowledgements of Financial Support: This study was supported by the Wuhan City Health Bureau of Medical Research project (No. WX18Y05)

Abbreviations: miR, MicroRNA; OS, osteosarcoma; CD133, Cluster of differentiation 133; Sox2, SRY-Box Transcription Factor 2; Oct4 octamer-binding transcription factor 4; GLUT1, glucose transporter 1; LDHA, lactate dehydrogenase A; HK2, hexokinase 2; PKM2, pyruvate kinase isomer 2; NC, negative control; qRT-PCR, quantitative reverse transcription polymerase chain reaction; $P C$, positive control; MTT, 3-(4,5-Dimethylthiazol-2-yl)-2,5-diphenyltetrazolium bromide; PBS, phosphate-buffered saline; AV-FITC, Annexin V-fluorescein isothiocyanate; $\mathrm{PI}$, propidium iodide; ATP, Adenosine triphosphate; GAPDH, glyceraldehyde-3-phosphate dehydrogenase; CSCs, cancer stem cells; n.s., No significance

\section{INTRODUCTION}

Osteosarcoma (OS) is the most prevalent primary bone tumor occurring in young adults and teenagers, exhibiting high aggressiveness and metastatic potential
(Li et al., 2019; Otoukesh et al., 2018). Epidemiological investigation indicated that three out of every million young adults and children suffer from OS, and the incidence reaches a peak at 11-15 years of age with six in every million children ( $\mathrm{Lu}$ et al., 2020). Although much effort has been dedicated to OS therapy, the five-year survival and prognosis of OS patients remain unimproved, particularly for patients with recurrence, multidrug resistance, or lung metastasis, due to insufficient diagnosis at the early stage and ineffective therapeutic approaches (Zhang et al., 2018). Therefore, it is necessary to identify novel clinical prognostic biomarkers and investigate the potential molecular mechanisms of OS to develop more effective therapeutic strategies (Tu et al., 2020).

MicroRNAs (miRNAs) are endogenous, non-coding, and single-stranded small molecular RNA containing about 22 nucleotides (Liu et al., 2018). They have demonstrated important functions in biological processes including cell proliferation, differentiation, and apoptosis (Najm et al., 2019). MiRNAs are involved in regulating gene expression by complete or incomplete complementary pairing with the 3'-untranslated regions of the target $\mathrm{mRNA}$, resulting in target mRNA degradation to silence specific genes or the inhibition of protein translation (Bartel, 2018). Numerous investigations have revealed that miRNAs are abnormally expressed in a variety of tumors, suggesting that they play an essential role in tumorigenesis and tumor progression (Iacona \& Lutz, 2019; Zhang et al., 2019). MiRNA-21 (miR-21) is located at $17 \mathrm{q} 23.2$ in the human chromosome and has exhibited proto-oncogenic activity (Li et al., 2018b; Ribas et al., 2012). Previous studies have shown that miR-21 was highly expressed in hepatocellular carcinoma (Chen et al., 2019), hepatoblastoma (Liu et al., 2019), and colorectal cancer (Xie et al., 2019). MiR-21 is also associated with the regulation of tumors cell proliferation and apoptosis through its interaction with target genes (Bautista-Sanchez et al., 2020). In addition, miR-21 was involved in the modulation of glycolysis and stemness maintenance in tumor cells by regulating relevant signaling pathways, thereby affecting tumor development. Zhu and others (Zhu et al., 2019) found that miR-21 inhibition suppressed glycolysis in breast cancer cells by regulating the phosphatidylinositol-4,5-bisphosphate 3-kinase/Akt pathway, in turn inhibiting breast cancer tumorigenesis. $\mathrm{Fu}$ and others (Fu et al., 2013) reported that NPV-LDE-225 inhibited the self-renewal of glioblastoma cells by downregulating the expression of Nanog, Oct4, and Sox 2 through suppressing miR-21. 
MiR-21 has been identified as a biomarker of poor prognosis in OS patients, as it was shown to be overexpressed in OS and associated with poor clinicopathological characteristics (Ren et al., 2016). However, the effect of miR-21 on glycolysis and stemness maintenance in OS cells remains to be elucidated. Moreover, evidence suggests that miR-21 was involved in the regulation of Wnt/ $\beta$-catenin signaling (Du et al., 2019), which is associated with glycolysis and stemness maintenance in tumor cells (Manna et al., 2014; Udoh et al., 2019). Whether miR-21 has an effect on the activity of the Wnt/ $\beta$ catenin pathway in OS cells remains unknown. On this basis, the current study was performed to explore the effect of miR-21-5p on glycolysis and stemness maintenance in $O S$ cells and clarify the underlying molecular mechanism involved therein.

\section{MATERIALS AND METHODS}

\section{Cell culture and transfection}

MG-63 human osteosarcoma cells were purchased from the Shanghai Institutes for Biological Sciences, Chinese Academy of Science and maintained in minimum essential medium supplemented with $10 \%$ fetal bovine serum (Gibco, MD, USA) at $37^{\circ} \mathrm{C}$ with $5 \% \mathrm{CO}_{2}$. After the cell confluence reached $70 \%$, the cells were transfected with commercially generated miR-21-5p mimic or inhibitor, or their corresponding negative control (NC) (40 pmol/ml, Ribo Biotechnology Co. LTD, Guangzhou, China) for $24 \mathrm{~h}$ using Lipofectamine ${ }^{\mathrm{TM}} 2000$ (Invitrogen, Carlsbad, CA, USA) according to the manufacture's instruction to overexpress or silence miR-21-5p expression. The transfection efficiency was then evaluated using quantitative reverse transcription polymerase chain reaction (qRT-PCR). Doxorubicin (200 nM; Kamata et al., 2017, Aladdin, Shanghai, China), a prevalent antineoplastic drug(Qin et al., 2018), served as positive control (PC).

\section{qRT-PCR}

Total RNA was extracted using Trizol (Ambion, Texas, USA) and reverse-transcribed into cDNA. The collected cDNA was then amplified using the SYBR Green PCR kit (KAPA Biosystems, USA) according to the manufacturer's protocol. The primer sequences are as follows: miR-21-5p forward: 5'-GGGTAGCTTATCAGACT-3', reverse: 5'-AACTGGTGTCGTGGAGTCGGC-3'; U6 forward: 5'-CTCGCT'TCGGCAGCACA-3', reverse: 5'-AACGCTTCACGAATTTGCGT-3'. U6 served as an endogenous control for miR-21-5p. The data were analyzed using the $2^{-\Delta \Delta \mathrm{Ct}}$ method (Livak and Schmittgen, 2001).

\section{3-(4,5-Dimethylthiazol-2-yl)-2,5-diphenyltetrazolium bromide (MTT) assay}

MTT was performed to evaluate the effect of miR21-5p on MG-63 cell proliferation. Harvested cells were seeded into a 96-well plate $\left(100 \mu \mathrm{l}\right.$ per well) at $3 \times 10^{3}$ cells/well and cultured overnight at $37^{\circ} \mathrm{C}$ with $5 \% \mathrm{CO}_{2}$. $10 \mu \mathrm{l}$ of MTT ( $5 \mathrm{mg} / \mathrm{ml}$, Solarbio, Beijing, China) was then added to the cells and maintained for $4 \mathrm{~h}$ at $37^{\circ} \mathrm{C}$ with $5 \% \quad \mathrm{CO}_{2}$. After the supernatant was removed, the cells were incubated in $150 \mu$ l of dimethylsulfoxide for $10 \mathrm{~min}$ and measured using a microplate reader (Allsheng, Hangzhou, China) at $490 \mathrm{~nm}$.

\section{Flow cytometry}

Flow cytometry was performed to detect the apoptosis and proportion of CD133-positive cells. For apoptosis: After treatment, $1 \times 10^{6}$ cells were collected and centrifuged at $4^{\circ} \mathrm{C}$ at $400 \times g$ for $5 \mathrm{~min}$, followed by resuspension in $1 \mathrm{ml}$ of phosphate-buffered saline (PBS) and centrifugation at $4^{\circ} \mathrm{C}$ at $400 \times g$ for $5 \mathrm{~min}$. Then, the cells were resuspended in $200 \mu \mathrm{l}$ of PBS and incubated with $10 \mu \mathrm{l}$ of Annexin V-fluorescein isothiocyanate (FITC) (BD, Shanghai, China) and $10 \mu \mathrm{l}$ of propidium iodide (PI) in the dark at $4^{\circ} \mathrm{C}$ for $30 \mathrm{~min}$. After 300 $\mu \mathrm{l}$ of PBS was added, the cells were evaluated by flow cytometry (ACEA Biosciences, San Diego, California, USA)

For the detection of CD133-positive cells: Cells $\left(1 \times 10^{6}\right)$ were resuspended in $100 \mu \mathrm{l}$ of PBS, followed by the addition of $2 \mu \mathrm{l}$ of phycoerythrin-conjugated CD133 antibodies (eBioscience, CA, USA). The cells were cultured in the dark at $4^{\circ} \mathrm{C}$ for $30 \mathrm{~min}$. Then, the cells were centrifuged at $4^{\circ} \mathrm{C}$ at $400 \times g$ for $5 \mathrm{~min}$, resuspended in the dark in $400 \mu \mathrm{l}$ of PBS, and evaluated by flow cytometry (ACEA Biosciences).

\section{Tumorsphere formation}

Cells were resuspended in Dulbecco's modified eagle medium containing 2\% B27 (Gibco), $20 \mathrm{ng} / \mathrm{ml}$ epidermal growth factor (PeproTech, New Jersey, USA), $10 \mu \mathrm{g} / \mathrm{ml}$ basic fibroblast growth factor (PeproTech), $5 \mu \mathrm{g} / \mathrm{ml}$ insulin (Solarbio), and $10 \mu \mathrm{g} / \mathrm{ml}$ transferrin (Solarbio). The cells were then incubated in ultra-low adherent 6-well dishes (Corning, New York, USA) at $2 \times 10^{6}$ cells $/ \mathrm{ml}(2$ $\mathrm{ml}$ per well) at $37^{\circ} \mathrm{C}$ with $5 \% \mathrm{CO}_{2}$ for 7 days. Thereafter, tumorspheres were observed under a DMIL LED microscope (Leica, Wetzlar, Germany).

\section{Biochemical detection}

Adenosine triphosphate (ATP) content (A095-1-1) and lactic acid levels (A019-2-1) in MG-63 cells were detected using corresponding commercial kits purchased from Nanjing Jiancheng Bioengineering Institute (Nanjing, China) following the manufacturer's instruction. Glucose uptake (361510) was evaluated using a corresponding commercial kit purchased from Shanghai Rongsheng Biotechnology Co., LTD following the manufacturer's instruction.

\section{Western blot}

Total proteins were extracted using radioimmunoprecipitation assay lysis buffer (Solarbio) and quantified using a bicinchoninic acid assay kit (Solarbio). $20 \mu \mathrm{g}$ of proteins were separated by sodium dodecyl sulfate-polyacrylamide gel electrophoresis (Solarbio) and transferred onto polyvinylidene fluoride membranes (Millipore, Massachusetts, USA). After blocking with $5 \%$ skim milk, the membranes were incubated for $1 \mathrm{~h}$ at room temperature with primary antibodies against sex determining region Y-box 2 (Sox2), octamer-binding transcription factor 4 (Oct4), Nanog, glucose transporter 1 (GLUT1), lactate dehydrogenase A (LDHA), hexokinase 2 (HK2), pyruvate kinase isomer 2 (PKM2), Wnt1, $\beta$-catenin, and GAPDH (all purchased from Myhalic Biotechnology Co., Ltd., Bioswamp, Wuhan, China). The membranes were then incubated for $1 \mathrm{~h}$ at room temperature with goat anti-rabbit IgG secondary antibodies (Myhalic Biotechnology Co., Ltd). GAPDH acted as the internal reference. 
A

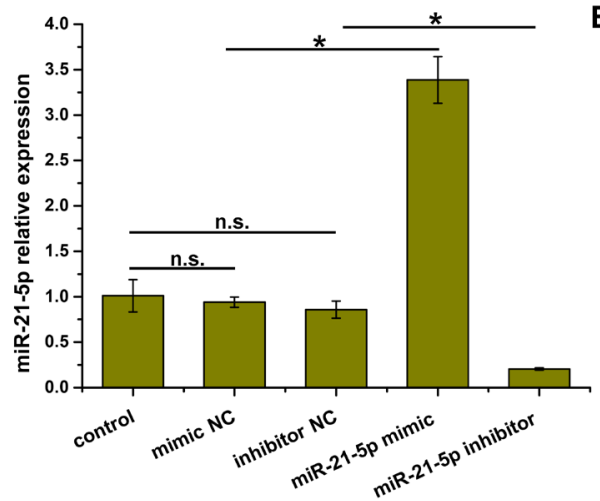

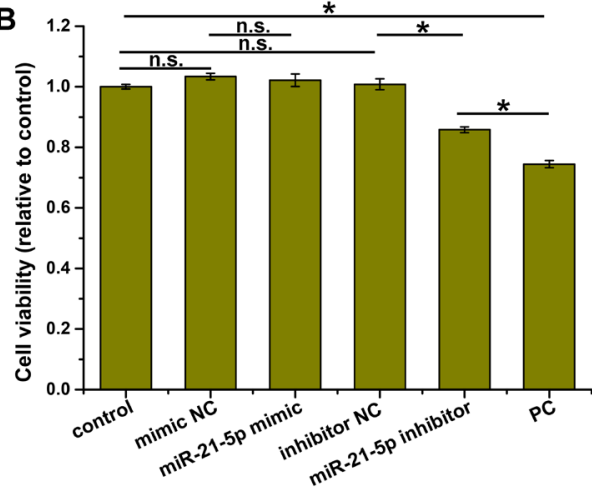

C
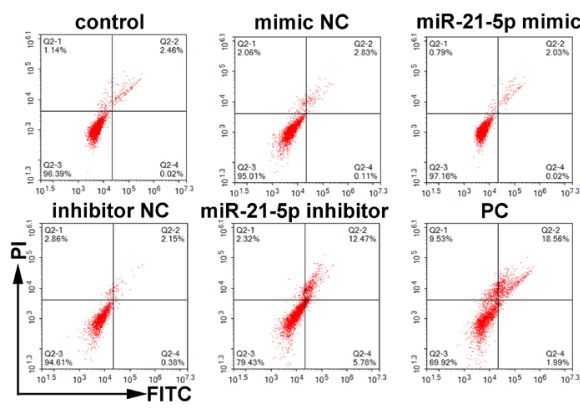

miR-21-5p inhibitor
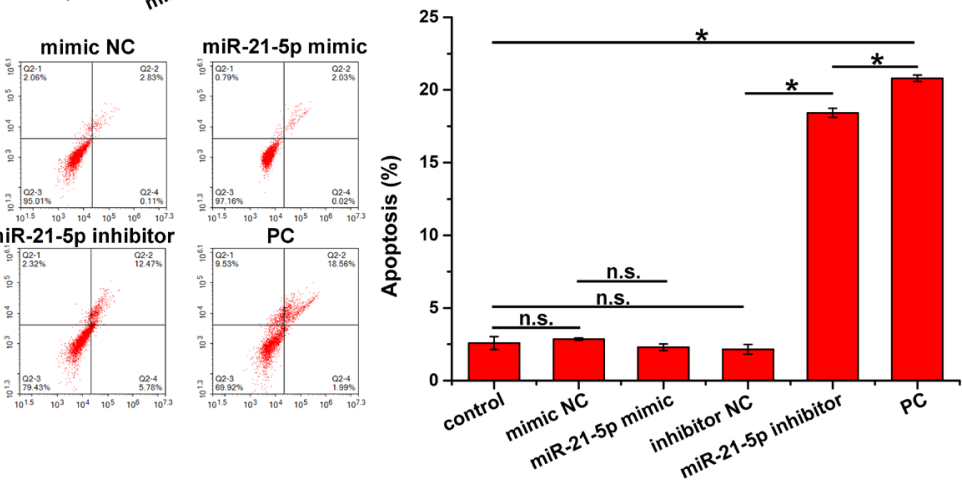

Figure 1. MiR-21-5p inhibition attenuates the viability and promotes the apoptosis of MG-63 cells.

(A) The expression of miR-21-5p in MG-63 cells was detected by qRT-PCR after miR-21-2p mimic and inhibitor transfection. (B) Detection of MG-63 cell viability using MTT assay. (C) Detection of MG-63 cell apoptosis by flow cytometry. Data represent the mean \pm S.D. ( $n=3$ ), ${ }^{*} P<0.05$.

\section{Statistical analysis}

Data are shown as the mean \pm standard deviation (S.D.). Differences among groups were analyzed using one-way analysis of variance followed by Tukey test. $P<0.05$ was considered to be statistically significant.

\section{RESULTS}

miR-21-5p inhibition attenuates proliferation while promoting apoptosis of MG-63 cells

As shown in Fig. 1A, the expression of miR-21-5p in MG-63 cells was increased and decreased by miR-21$5 \mathrm{p}$ mimic and inhibitor transfection, respectively. The corresponding NC showed no effect. Compared to the control or NC, the viability of MG-63 cells (Fig. 1B, $P<0.05)$ was decreased by miR-21-5p inhibition, while apoptosis (Fig. 1C, $P<0.05$ ) was enhanced. The effect of miR-21-5p inhibition on cell viability and apoptosis were similar to that of doxorubicin. These results demonstrated that miR-21-5p inhibition attenuates the proliferation while promoting the apoptosis of MG-63 cells.

\section{miR-21-5p inhibition attenuates stemness maintenance in MG-63 cells}

Tumorspheres are spherical and solid structures originating from cancer stem cells. Figure 2A indicates that miR-21-5p inhibition suppressed tumorsphere formation of MG-63 cells. Flow cytometry demonstrated that $\mathrm{miR}-21-5 \mathrm{p}$ inhibition reduced the proportion of MG-63 cells with positive expression of CD133 (Fig. 2B), a specific marker of cancer stem cells (Bi et al.,
2016). In addition, the expression of stem cell-related proteins was evaluated. miR-21-5p inhibition attenuated the protein expression of Sox2, Oct4, and Nanog in MG-63 cells, while miR-21-5p overexpression showed an opposite effect (Fig. 2C). The effect of miR-21-5p inhibition on the stemness of MG-63 cells was similar to that of doxorubicin. These results indicated that miR-21-5p inhibition attenuates stemness maintenance in MG-63 cells

\section{miR-21-5p inhibition attenuates the Warburg effect in MG-63 cells}

Compared to the control and $\mathrm{NC}$, glucose uptake (Fig. 3A), lactic acid generation (Fig. 3B), ATP content (Fig. 3C), and the expression of metabolism-related enzymes associated with the Warburg effect (LDHA, GLUT1, PKM2, and HK2) (Fig. 3D and E) were decreased by miR-21-5p inhibition $(P<0.05)$, but increased by miR-21-5p mimics $(P<0.05)$. The effect of miR-21-5p inhibition on MG-63 cells was similar to that of doxorubicin. These results indicated that miR-21-5p inhibition attenuates the Warburg effect in MG-63 cells.

\section{miR-21-5p inhibition attenuates the activity of Wnt/ $\beta$ catenin signaling}

As shown in Fig. 4, the expression of Wnt and $\beta$-catenin was decreased by miR-21-5p inhibitors compared to that of the control or inhibitor NC groups $(P<0.05)$, while it was increased by miR-21-5p mimics compared to that of the control or mimic NC groups $(P<0.05)$. These results demonstrated that miR-21-5p inhibition attenuates the activity of $\mathrm{Wnt} / \beta$-catenin signaling. 
A

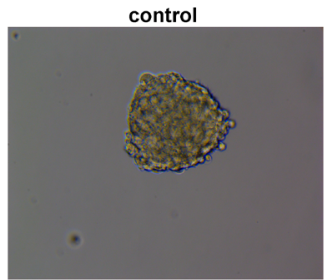

inhibitor NC

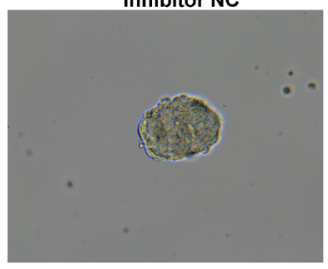

mimic NC

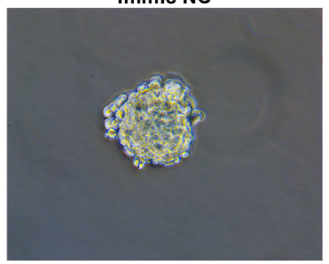

miR-21-5p inhibitor

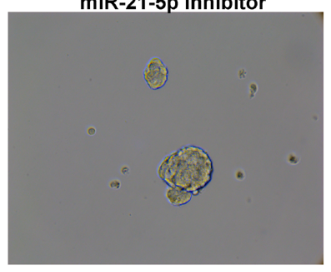

miR-21-5p mimic

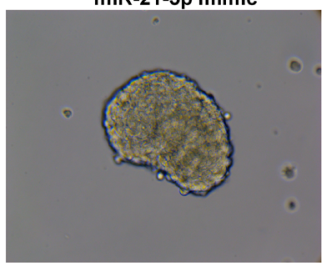

PC

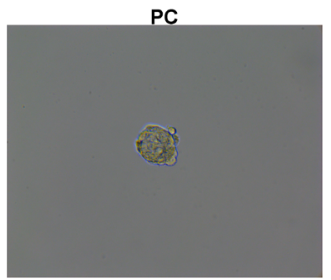

B
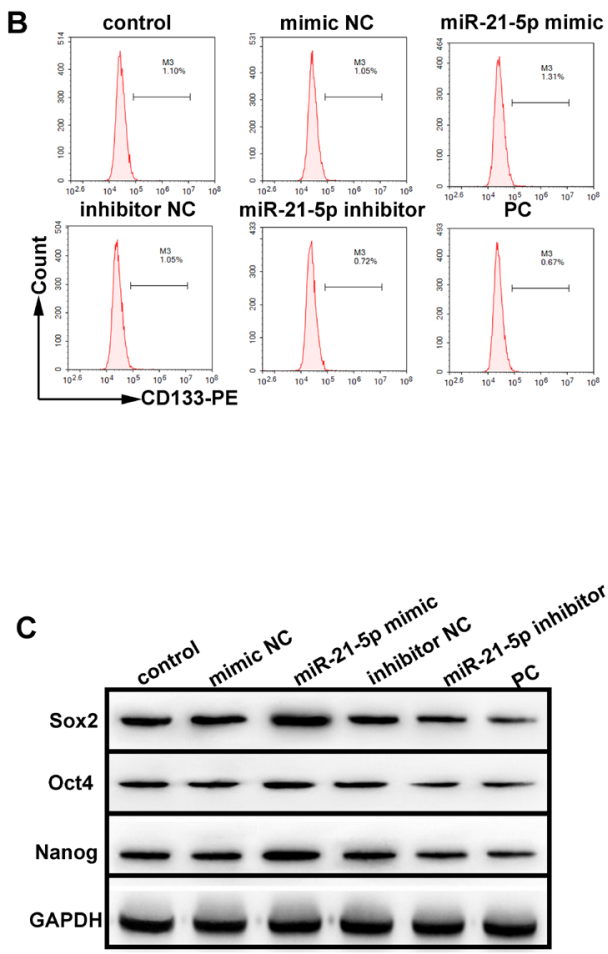
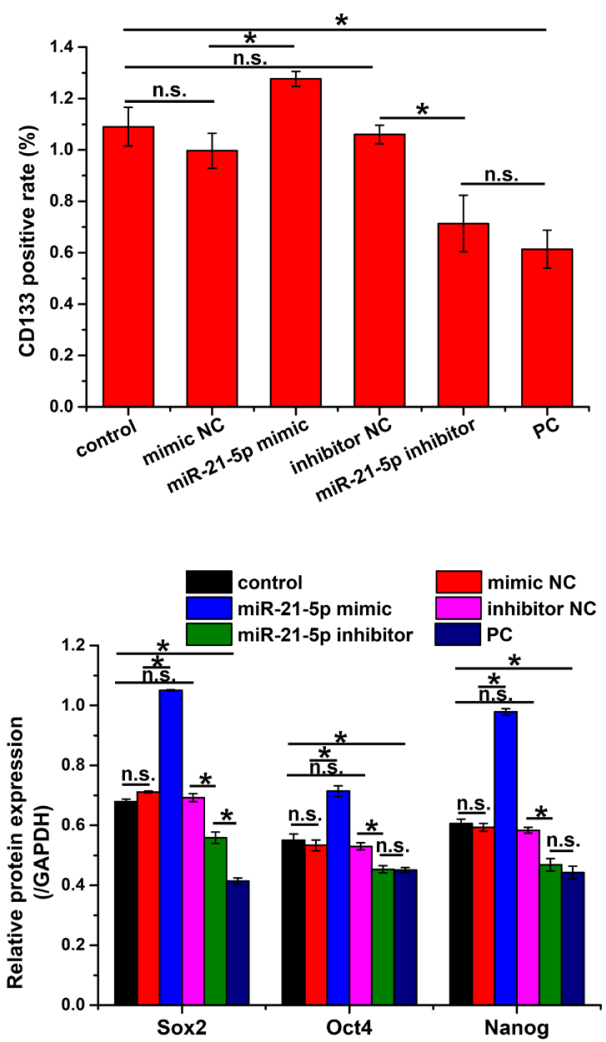

Figure 2. MiR-21-5p inhibition attenuates the stemness maintenance of MG-63 cells.

(A) Tumorsphere formation of MG-63 cells after miR-21-2p mimic and inhibitor transfection. (B) Proportion of CD133+ cells in MG-63 cells after miR-21-2p mimic and inhibitor transfection, detected by flow cytometry. (C) Relative protein expression of Oct4, Sox2, and Nanog in MG-63 cells after miR-21-2p mimic and inhibitor transfection, detected by western blot. Data represent the mean $\pm S . D$. ( $n=3$ ), * $P<0.05$.

\section{DISCUSSION}

The phenomenon wherein cancer cells preferentially utilize glucose for energy via glycolysis, even under aerobic conditions, was identified as the "Warburg effect" (Spencer \& Stanton, 2019). It is associated with oncogenic expression, abnormal expression of glycometabolic enzymes, the tumor microenvironment, and tumor development. Thus, the Warburg effect has been widely characterized as a hallmark of tumor, and anticancer therapeutic strategies targeting the Warburg ef- fect are being development (Li et al., 2018a). Compared to non-tumorigenic cells, tumorigenic cells exhibit dramatically increased glucose uptake, followed by the rapid conversion of pyruvate into lactic acid even under aerobic conditions, during which the glycolysis rate is upregulated and ATP is produced (Lebelo et al., 2019; $\mathrm{Lu}$ et al., 2015). Evidence has suggested that the glycolytic process is associated with GLUTs, LDHA and rate-limiting enzymes including $\mathrm{HK} 2$, and PKM2 (Ruzzo et al., 2020; Wiese \& Hitosugi, 2018). GLUTs are involved in the transport of glucose across the plasma 

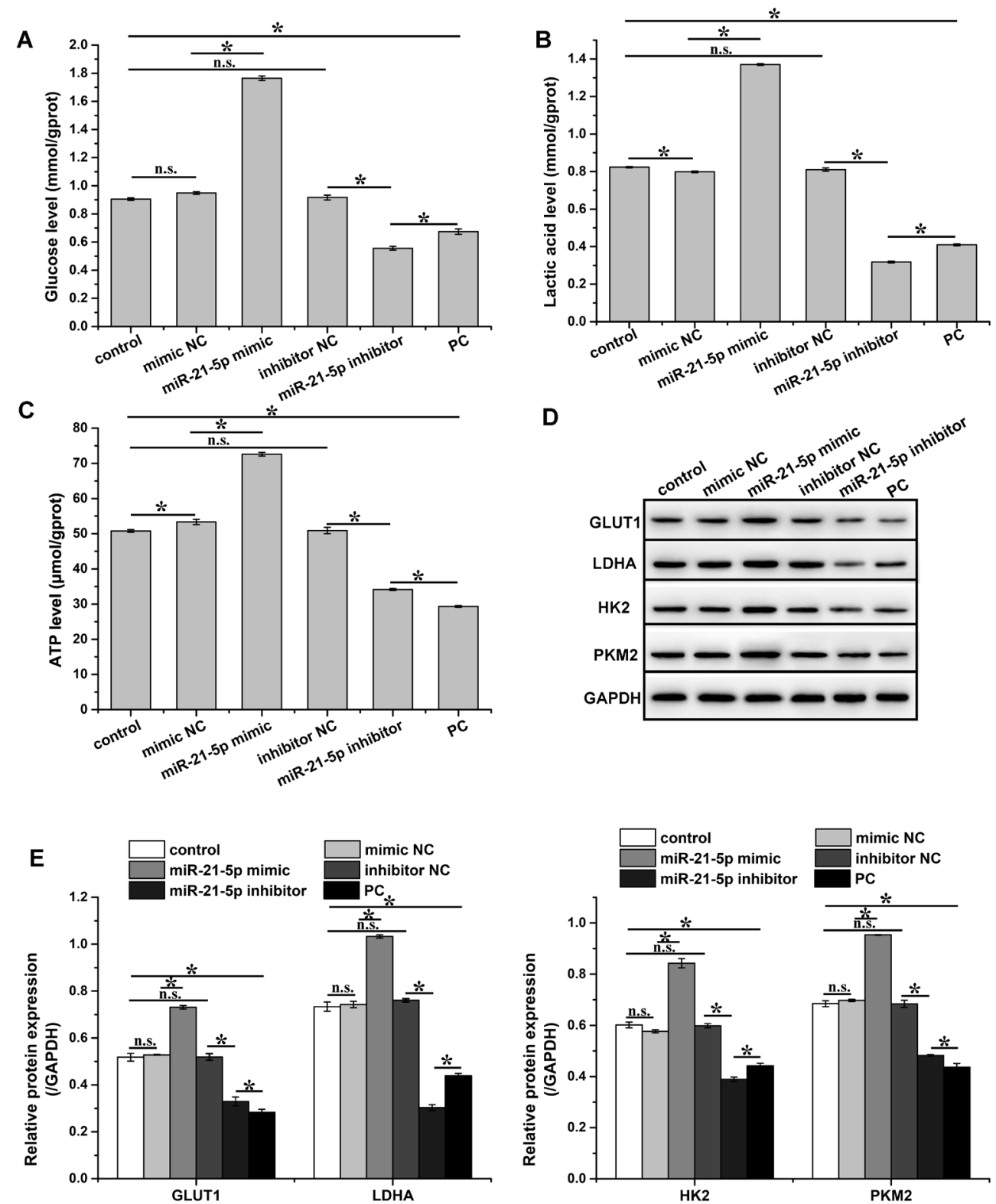

Figure 3 MiR-21-5p inhibition attenuates the Warburg effect in MG-63 cells.

(A) Glucose uptake, (B) lactic acid level, (C) and ATP level in MG-63 cells after miR-21-2p mimic and inhibitor transfection, detected using corresponding kits. (D) Relative protein expression of GLUT1, LDHA, HK2, and PKM2 in MG-63 cells after miR-21-2p mimic and inhibitor transfection, detected by western blot. (E) Quantification of (D). Data represent the mean \pm S.D. $(n=3),{ }^{*} P<0.05$.

membrane, thereby mediating glucose uptake (Barron et al., 2016). GLUT1 is upregulated in numerous types of cancer and can act as a target for anti-cancer treatment because of its effect on glucose uptake (Lebelo et al., 2019). HK2 facilitates glucose phosphorylation to generate glucose-6-phosphate, which is the first irreversible step in the glucose metabolism pathway, thereby enhancing aerobic glycolysis (Xu et al., 2019). Thus, it is identified as a vital player in the Warburg effect, and like GLUT1, it has been regarded as a therapeutic target for tumors (Patra et al., 2013). Previous studies have found that HK2 deficiency exhibited remarkable reduced LDHA expression, a crucial functional enzyme in glycolysis that promotes pyruvate conversion into lactic acid (Pathria et al., 2018; Xu et al., 2019). PKM2 is another important component of the Warburg effect that promotes rapid energy generation during glycolysis (Palsson-McDermott \& O’Neill, 2013). Overexpression of HK2, PKM2, LDHA, and GLUT1 contributed to the Warburg effect in cancer cells (Yan et al., 2019; Yu et al., 2019). The present work showed that miR-21-5p inhibition suppressed the expression of HK2, PKM2, LDHA, and GLUT1, thereby inhibiting glucose uptake and the levels of lactic acid and ATP in OS cells, indicating that miR-21-5p inhibition attenuates the Warburg effect in OS cells. As for HK2, PKM2, LDHA, and GLUT1 proteins detection, GAPDH, another glycolytic enzyme (Liao et al., 2019), was used as the loading control. The present study showed no effect of miR-21-5p on GAPDH expression, as indicated by no statistical difference of gray value in different group, which was in consistence with previous studies that miR-21-5p inhibition or overexpression did not affect GAPDH expression (Huang et al., 2021; Zhang et al., 2021)

As an important characteristic of metabolic reprogramming in tumor cells, the Warburg effect contrib- 

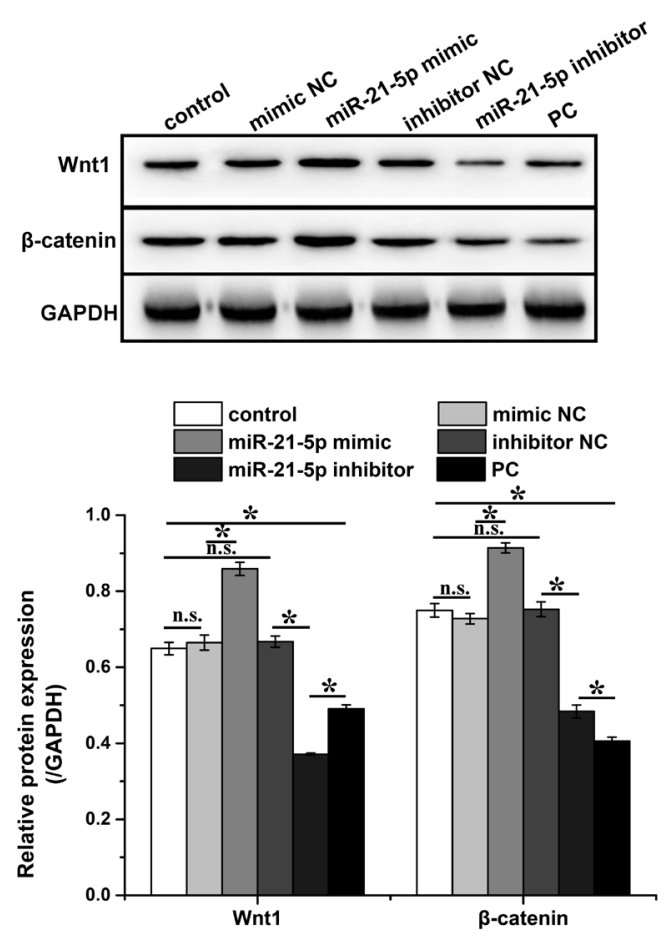

Figure 4. MiR-21-5p inhibition attenuates the activity of Wnt/ $\beta$ catenin signaling pathway.

Relative protein expression of Wnt 1 and $\beta$-catenin in MG-63 cells after miR-21-2p mimic and inhibitor transfection, detected by western blot. Data represent the mean \pm S.D. $(n=3),{ }^{*} P<0.05$.

utes to growth, survival, and proliferation of cancer stem cells (CSCs) as well as enables the maintenance of the CSCs state (Vaupel et al., 2019). Tumorigenic cells with stem cell-like characteristics are regarded as CSCs, which have strong multi-directional differentiation potential and self-renewal ability (Ayob \& Ramasamy, 2018; Hajizadeh et al., 2019). Emerging evidence has demonstrated that the capacity of tumor reproduction and development depends on the stem-like characteristics of cancer cells, which allow cells to remain in a dormant state and retain the ability to evade therapeutic drugs and metastasis (Adorno-Cruz et al., 2015). Therefore, inhibiting the maintenance of the CSC state or the proportion of CSCs in cancer cells is an effective strategy for cancer treatment (Yoshida \& Saya, 2016). The current study revealed that miR-21-5p inhibition suppressed tumorsphere formation (initiated from CSCs) of OS cells and reduced the proportion of MG-63 cells with positive expression of CD133, a specific marker of CSCs (Bi et al., 2016). In addition, miR-21-5p inhibition attenuated the protein expression of Sox2, Oct4, and Nanog, which are key transcription factors that keep the self-renewal of CSC, in turn regulating cancer recurrence, progression, and drug resistance (Hattermann et al., 2016). Taken together, these results indicate that miR-21-5p inhibition suppressed the stemness maintenance in OS cells, as demonstrated by the decrease in the proportion of CD133-positive OS cells and the downregulation of Sox 2 , Oct4, and Nanog. Whether this is associated with the suppression of the Warburg effect induced by miR-21-5p inhibition needs to be further elucidated.

The current results also demonstrated that miR21-5p inhibition attenuates the activity of the Wnt/ $\beta$ catenin signal pathway, which has been shown to be associated with glycolysis and stemness maintenance in tumor cells (Manna et al., 2014; Udoh et al., 2019). The activation of $\mathrm{Wnt} / \beta$-catenin signaling promoted the Warburg effect in tumor cells by increasing the level of acetyl-coenzyme A and ATP level produced by the oxidation of fatty acids (Manna et al., 2014). Additionally, it was previously reported that Wnt/ $\beta$ catenin pathway inactivation may assist in eradicating OS stem cells by regulating CD133, Sox2, Oct4, and Nanog expression (Yi et al., 2015). In agreement with previous research, the current study indicates that miR-21-5p inhibition suppresses the Warburg effect and stemness maintenance in OS cells, possibly by Wnt/ $\beta$-catenin signal pathway.

In conclusion, the current study provides insight suggesting that miR-21-5p inhibition suppresses the Warburg effect in OS cells by regulating the expression of proteins involved in the Warburg effect (HK2, PKM2, LDHA, and GLUT1), thereby inhibiting glucose uptake and lactic acid and ATP level in OS cells. In addition, miR-21-5p inhibition suppresses stemness maintenance in OS cells by regulating the expression of transcription factors that promote the self-renewal of CSCs (Sox2, Oct4, and Nanog). The underlying mechanism might be associated with the Wnt/ $\beta$ catenin signaling pathway.

\section{Acknowledgement}

Not applicable.

\section{Conflict of interest}

The authors declare that no conflict of interest is associated with this work.

\section{Ethics approval and consent to participate}

Not applicable.

\section{Availability of data and materials}

All data generated or analyzed during this study are included in this published article.

\section{Authors' contributions}

Study design: Ziyan Wu, Yi Yu. Experiment production: Ziyan Wu, Zhong Zhou, Weiguo Zhang. Data collection and molecular analysis: Ziyan Wu, Zhong Zhou. Manuscript writing and editing: Ziyan Wu, Zhong Zhou, $\mathrm{Yi} \mathrm{Yu}$

\section{REFERENCES}

Adorno-Cruz V, Kibria G, Liu X, Doherty M, Junk DJ, Guan D, Hubert C, Venere M, Mulkearns-Hubert E, Sinyuk M, Alvarado A, Caplan AI, Rich J, Gerson SL, Lathia J, Liu H (2015) Cancer stem cells: targeting the roots of cancer, seeds of metastasis, and sources of therapy resistance. Cancer Res 75: 924-929. https://doi. org/10.1158/0008-5472.CAN-14-3225

Ayob AZ, Ramasamy TS (2018) Cancer stem cells as key drivers of tumour progression. J Biomed Sci 25: 20. https://doi.org/10.1186/ s12929-018-0426-4

Barron CC, Bilan PJ, Tsakiridis T, Tsiani E (2016) Facilitative glucose transporters: Implications for cancer detection, prognosis and treatment. Metabolism 65: 124-139. https://doi.org/10.1016/j.metabol.2015.10.007

Bartel DP (2018) Metazoan MicroRNAs. Cell 173: 20-51. https://doi. org/10.1016/j.cell.2018.03.006

Bautista-Sanchez D, Arriaga-Canon C, Pedroza-Torres A, De La RosaVelazquez IA, Gonzalez-Barrios R, Contreras-Espinosa L, MontielManriquez R, Castro-Hernandez C, Fragoso-Ontiveros V, AlvarezGomez RM, Herrera LA (2020) The promising role of miR-21 as a cancer biomarker and its importance in RNA-based therapeu- 
tics. Mol Ther Nucleic Acids 20: 409-420. https://doi.org/10.1016/j. omtn.2020.03.003

Bi Y, Meng Y, Wu H, Cui Q, Luo Y, Xue X (2016) Expression of the potential cancer stem cell markers CD133 and CD44 in medullary thyroid carcinoma: A ten-year follow-up and prognostic analysis. $J$ Surg Oncol 113: 144-151. https://doi.org/10.1002/jso.24124

Chen S, Yang C, Sun C, Sun Y, Yang Z, Cheng S, Zhuge B (2019) miR-21-5p Suppressed the sensitivity of hepatocellular carcinoma cells to cisplatin by targeting FASLG. DNA Cell Biol 38: 865-873. https://doi.org/10.1089/dna.2018.4529

Du Q, Zhang X, Zhang X, Wei M, Xu H, Wang S (2019) Propofol inhibits proliferation and epithelial-mesenchymal transition of MCF-7 cells by suppressing miR-21 expression. Artif Cells Nanomed Biotechnol 47: 1265-1271. https://doi.org/10.1080/21691401.2019.1594000

Fu J, Rodova M, Nanta R, Meeker D, Van Veldhuizen PJ, Srivastava RK, Shankar S (2013) NPV-LDE-225 (Erismodegib) inhibits epithelial mesenchymal transition and self-renewal of glioblastoma initiating cells by regulating miR-21, miR-128, and miR-200. Neuro Oncol 15: 691-706. https://doi.org/10.1093/neuonc/not011

Hajizadeh F, Okoye I, Esmaily M, Ghasemi Chaleshtari M, Masjedi A, Azizi G, Irandoust M, Ghalamfarsa G, Jadidi-Niaragh F (2019) Hypoxia inducible factors in the tumor microenvironment as therapeutic targets of cancer stem cells. Life Sci 237: 116952. https://doi. org/10.1016/j.lfs.2019.116952

Hattermann K, Fluh C, Engel D, Mehdorn HM, Synowitz M, Mentlein $\mathrm{R}$, Held-Feindt J (2016) Stem cell markers in glioma progression and recurrence. Int J Oncol 49: 1899-1910. https://doi.org/10.3892/ ijo. 2016.3682

Huang Y, Yang Y, Wang J, Yao S, Yao T, Xu Y, Chen Z, Yuan P, Gao J, Shen S, Ma J (2021) miR-21-5p targets SKP2 to reduce osteoclastogenesis in a mouse model of osteoporosis. J Biol Chem 296: 100617. https://doi.org/10.1016/j.jbc.2021.100617

Iacona JR, Lutz CS (2019) miR-146a-5p: Expression, regulation, and functions in cancer. Wiley Interdiscip Rev RNA 10: e1533. https://doi. org/10.1002/wrna.1533

Kamata E, Kawamoto T, Ueha T, Hara H, Fukase N, Minoda M, Morishita M, Takemori T, Fujiwara S, Nishida K, Kuroda R, Kurosaka M, Akisue T (2017) Synergistic effects of a Smac mimetic with doxorubicin against human osteosarcoma. Anticancer Res 37: 60976106. https://doi.org/10.21873/anticanres.12058

Lebelo MT, Joubert AM, Visagie MH (2019) Warburg effect and its role in tumourigenesis. Arch Pharm Res 42: 833-847. https://doi. org/10.1007/s12272-019-01185-2

Li L, Liang Y, Kang L, Liu Y, Gao S, Chen S, Li Y, You W, Dong Q, Hong T, Yan Z, Jin S, Wang T, Zhao W, Mai H, Huang J, Han X, Ji Q, Song Q, Yang C, Zhao S, Xu X, Ye Q (2018a) Transcriptional regulation of the Warburg effect in cancer by SIX1. Cancer Cell 33: 368-385 e7. https://doi.org/10.1016/j.ccell.2018.01.010

Li Q, Li B, Li Q, Wei S, He Z, Huang X, Wang L, Xia Y, Xu Z, Li Z, Wang W, Yang L, Zhang D, Xu Z (2018b) Exosomal miR-21-5p derived from gastric cancer promotes peritoneal metastasis via mesothelial-to-mesenchymal transition. Cell Death Dis 9: 854. https:// doi.org/10.1038/s41419-018-0928-8

Li SQ, Tu C, Wan L, Chen RQ, Duan ZX, Ren XL, Li ZH (2019) FGF-induced LHX9 regulates the progression and metastasis of osteosarcoma via FRS2/TGF-beta/beta-catenin pathway. Cell Div 14: 13. https://doi.org/10.1186/s13008-019-0056-6

Liao ST, Han C, Xu DQ, Fu XW, Wang JS, Kong LY (2019) 4-Octyl itaconate inhibits aerobic glycolysis by targeting GAPDH to exert anti-inflammatory effects. Nat Commun 10: 5091. https://doi, org/10.1038/s41467-019-13078-5

Liu H, Lei C, He Q, Pan Z, Xiao D, Tao Y (2018) Nuclear functions of mammalian MicroRNAs in gene regulation, immunity and cancer. Mol Cancer 17: 64. https://doi.org/10.1186/s12943-018-0765-5

Liu L, Wang L, Li X, Tian P, Xu H, Li Z, Liu E (2019) Effect of miR21 on apoptosis in hepatoblastoma cell through activating ASPP2/ p38 signaling pathway in vitro and in vivo. Artif Cells Nanomed Biotechnol 47: 3729-3736. https://doi.org/10.1080/21691401.2019.1664561

Livak KJ, Schmittgen TD (2001) Analysis of relative gene expression data using real-time quantitative PCR and the 2(-Delta Delta C(T)) Method. Methods 25: 402-8. https://doi.org/10.1006/meth.2001.1262

Lu J, Tan M, Cai Q (2015) The Warburg effect in tumor progression: mitochondrial oxidative metabolism as an anti-metastasis mechanism. Cancer Lett 356: 156-164. https://doi.org/10.1016/j.canlet.2014.04.001

Lu KH, Lu EW, Lin CW, Yang JS, Yang SF (2020) New insights into molecular and cellular mechanisms of zoledronate in human osteosarcoma. Pharmacol Ther 214: 107611. https://doi.org/10.1016/j. pharmthera.2020.107611

Manna SK, Tanaka N, Krausz KW, Haznadar M, Xue X, Matsubara T, Bowman ED, Fearon ER, Harris CC, Shah YM, Gonzalez FJ (2014) Biomarkers of coordinate metabolic reprogramming in colorectal tumors in mice and humans. Gastroenterology 146: 1313-1324. https://doi.org/10.1053/j.gastro.2014.01.017

Najm A, Blanchard F, Le Goff B (2019) Micro-RNAs in inflammatory arthritis: From physiopathology to diagnosis, prognosis and thera- peutic opportunities. Biochem Pharmacol 165: 134-144. https://doi. org/10.1016/j.bcp.2019.02.031

Otoukesh B, Boddouhi B, Moghtadaei M, Kaghazian P, Kaghazian M (2018) Novel molecular insights and new therapeutic strategies in osteosarcoma. Cancer Cell Int 18: 158. https://doi.org/10.1186/ s12935-018-0654-4

Palsson-McDermott EM, O’Neill LA (2013) The Warburg effect then and now: from cancer to inflammatory diseases. Bioessays 35: 965 973. https://doi.org/10.1002/bies.201300084

Pathria G, Scott DA, Feng Y, Sang Lee J, Fujita Y, Zhang G, Sahu AD, Ruppin E, Herlyn M, Osterman AL, Ronai ZA (2018) Targeting the Warburg effect via LDHA inhibition engages ATF4 signaling for cancer cell survival. EMBO J 37. https://doi.org/10.15252/ embj.201899735

Patra KC, Wang Q, Bhaskar PT, Miller L, Wang Z, Wheaton W, Chandel N, Laakso M, Muller WJ, Allen EL, Jha AK, Smolen GA, Clasquin MF, Robey B, Hay N (2013) Hexokinase 2 is required for tumor initiation and maintenance and its systemic deletion is therapeutic in mouse models of cancer. Cancer Cell 24: 213-228. https:// doi.org/10.1016/j.ccr.2013.06.014

Qin L, Wu L, Jiang S, Yang D, He H, Zhang F, Zhang P (2018) Multifunctional micelle delivery system for overcoming multidrug resistance of doxorubicin. J Drug Target 26: 289-295. https://doi.org/10. 1080/1061186X.2017.1379525

Ren X, Shen Y, Zheng S, Liu J, Jiang X (2016) miR-21 predicts poor prognosis in patients with osteosarcoma. Br J Biomed Sci 73: 158162. https://doi.org/10.1080/09674845.2016.1220710

Ribas J, Ni X, Castanares M, Liu MM, Esopi D, Yegnasubramanian S, Rodriguez R, Mendell JT, Lupold SE (2012) A novel source for miR-21 expression through the alternative polyadenylation of VMP1 gene transcripts. Nucleic Acids Res 40: 6821-6833. https:// doi.org/10.1093/nar/gks308

Ruzzo A, Graziano F, Bagaloni I, Di Bartolomeo M, Prisciandaro M, Aprile G, Ongaro E, Vincenzi B, Perrone G, Santini D, Fornaro L, Vivaldi C, Tomasello G, Loupakis F, Lonardi S, Fassan M, Valmasoni M, Sarti D, Lorenzini P, Catalano V, Bisonni R, Del Prete M, Collina G, Magnani M (2020) Glycolytic competence in gastric adenocarcinomas negatively impacts survival outcomes of patients treated with salvage paclitaxel-ramucirumab. Gastric Cancer 23: 1064 1074. https://doi.org/10.1007/s10120-020-01078-0

Spencer NY, Stanton RC (2019) The Warburg effect, lactate, and nearly a century of trying to cure cancer. Semin Nephrol 39: 380-393. https://doi.org/10.1016/j.semnephrol.2019.04.007

Tu C, He J, Qi L, Ren X, Zhang C, Duan Z, Yang K, Wang W, Lu Q, Li Z (2020) Emerging landscape of circular RNAs as biomarkers and pivotal regulators in osteosarcoma. J Cell Physiol 235: 90379058. https://doi.org/10.1002/jcp.29754

Udoh K, Parte S, Carter K, Mack A, Kakar SS (2019) Targeting of lung cancer stem cell self-renewal pathway by a small molecule verrucarin J. Stem Cell Rev Rep 15: 601-611. https://doi.org/10.1007/ s12015-019-09874-7

Vaupel P, Schmidberger H, Mayer A (2019) The Warburg effect: essential part of metabolic reprogramming and central contributor to cancer progression. Int J Radiat Biol 95: 912-919. https://doi.org/10 $.1080 / 09553002.2019 .1589653$

Wiese EK, Hitosugi T (2018) Tyrosine kinase signaling in cancer metabolism: PKM2 paradox in the Warburg effect. Front Cell Dev Biol 6: 79. https://doi.org/10.3389/fcell.2018.00079

Xie L, Li S, Jin J, He L, Xu K, Zhu L, Du M, Liu Y, Chu H, Zhang Z, Wang M, Shi D, Gu D, Ni M (2019) Genetic variant in miR-21 binding sites is associated with colorectal cancer risk. J Cell Mol Med 23: 2012-2019. https://doi.org/10.1111/jcmm.14104

Xu F, Yan JJ, Gan Y, Chang Y, Wang HL, He XX, Zhao Q (2019) miR-885-5p Negatively regulates Warburg effect by silencing hexokinase 2 in liver cancer. Mol Ther Nucleic Acids 18: 308-319. https://doi.org/10.1016/j.omtn.2019.09.002

Yan L, Raj P, Yao W, Ying H (2019) Glucose metabolism in pancreatic cancer. Cancers (Basel) 11: 1406. https://doi.org/10.3390/cancers11101460

Yi XJ, Zhao YH, Qiao LX, Jin CL, Tian J, Li QS (2015) Aberrant Wnt/beta-catenin signaling and elevated expression of stem cell proteins are associated with osteosarcoma side population cells of high tumorigenicity. Mol Med Rep 12: 5042-5048. https://doi. org/10.3892/mmr.2015.4025

Yoshida GJ, Saya H (2016) Therapeutic strategies targeting cancer stem cells. Cancer Sci 107: 5-11. https://doi.org/10.1111/cas.12817

Yu W, Yang Z, Huang R, Min Z, Ye M (2019) SIRT6 promotes the Warburg effect of papillary thyroid cancer cell BCPAP through reactive oxygen species. Onco Targets Ther 12: 2861-2868. https://doi. org/10.2147/OT'T.S194256

Zhang L, Liao Y, Tang L (2019) MicroRNA-34 family: a potential tumor suppressor and therapeutic candidate in cancer. J Exp Clin Cancer Res 38: 53. https://doi.org/10.1186/s13046-019-1059-5

Zhang Y, Huang H, Liu W, Liu S, Wang XY, Diao ZL, Zhang AH, Guo W, Han X, Dong X, Katilov O (2021) Endothelial progenitor cells-derived exosomal microRNA-21-5p alleviates sepsis-induced 
acute kidney injury by inhibiting RUNX1 expression. Cell Death Dis 12: 335. https://doi.org/10.1038/s41419-021-03578-y

Zhang YY, Kong LQ, Zhu XD, Cai H, Wang CH, Shi WK, Cao MQ, Li XL, Li KS, Zhang SZ, Chai ZT, Ao JY, Ye BG, Sun HC (2018)

CD31 regulates metastasis by inducing epithelial-mesenchymal transition in hepatocellular carcinoma via the ITGB1-FAK-Akt signal- ing pathway. Cancer Lett 429: 29-40. https://doi.org/10.1016/j.canlet.2018.05.004

Zhu M, Wang X, Gu Y, Wang F, Li L, Qiu X (2019) MEG3 overexpression inhibits the tumorigenesis of breast cancer by downregulating miR-21 through the PI3K/Akt pathway. Arch Biochem Biophys 661: 22-30. https://doi.org/10.1016/j.abb.2018.10.021 